\title{
Editorial
}

\section{New Frontiers for International Perspectives in Psychology}

Building Forward Better

\author{
Stuart C. Carr ${ }^{1}$ and Ines Meyer ${ }^{2}$ \\ 'School of Psychology, Massey University, Aukland, New Zealand \\ ${ }^{2}$ School of Management Studies, University of Cape Town, Rondebusch, South Africa
}

2021 is not only the start of a new year, but it is also the start of a new publisher for International Perspectives in Psychology: Research, Practice, Consultation (IPP). We are delighted to be publishing with, and to be published by, Hogrefe. In our last editorial of 2020, we focused on building back better (Carr \& Meyer, 2020). In this issue of IPP, by contrast, we focus on building forward better, through our new publishing partnership with Hogrefe. Already, for example, Hogrefe has just announced a very exciting and innovative development for the road ahead - researchers from most of the relevant scientific and research institutions in Germany, a total of 113 institutions, will be able to publish their articles in Hogrefe journals open access from 2021 onwards, at no additional cost (Hogrefe, 2020). We therefore call on contributors across Germany, and more importantly your international colleagues and research partners, to consider submitting your international perspectives in psychology to IPP!

Speaking of international ethos, diversity, and inclusion, this issue is incredibly diverse, not only in topics but also in the places from which, and in which, they are grounded. They span a range of methods and approaches. They speak to a variety of interconnected goals and values espoused in the journal's ambit and ethos. They include a perspective from the creative arts on political change in Puerto Rico (Espada-Brignoni \& Alfaro, 2021) and, in response to an earlier call for a special issue on populism, para-social relationships with populist leaders across (and within) Indonesia, the United States, and in New Zealand (Hakim $\& \mathrm{Liu}, 2021)$. We have further articles on the psychology of shame, building more inclusive human services, among Pakistani immigrants in Canada (Collardeau et al., 2021); and on the potential role of micronutrients in helping to combat traumatic stress following events like the Christchurch shootings and other natural and manmade disasters (Rucklidge et al, 2021). Finally, we have a Policy Brief on how to streamline access to host country humanitarian services like healthcare for refugees from Syria in Turkey (Chen, 2021). Empowerment and change, mobility and recovery from disasters, and building forward into more inclusive human services - these are all hallmark themes in IPP and our home, Division 52 - International Psychology (https://www.apa.org/about/division/div52).

As we turn now to face forwards into 2021, we are very excited and humbled to be working together with Hogrefe to build forward better. Keep your eyes open for our forthcoming special issues across a range of topics, from decent work and global changes in the world of work, on women during COVID-19, and psychology during the COVID-19 pandemic (https://www.hogrefe.com/us/ journal/international-perspectives-in-psychology-researchpractice-consultation). Above all, please do consider sending us your ideas for future special issues, and formats, and your research articles and policy briefs. Feel free to contact us directly on S.C.Carr@Massey.ac.nz and/or I.Meyer@uct.ac.za. We warmly welcome your innovative ideas and feedback on the contents of the journal, present and future, and look forward to building forward better with all of us during the new year ahead.

\section{References}

Carr, S. C., \& Meyer, I. (2020). Building back better with international perspectives in psychology. International Perspectives in Psychology: Research, Practice, Consultation, 9(4), 191-192. https://doi.org/10.1037/ipp0000148

Chen, E. C. (2021). Syrian refugee access to and quality of healthcare in Turkey: A call to streamline and simplify the process. International Perspectives in Psychology: Research, Practice, Consultation, 10(1), 55-57. https://doi.org/10.1027/2157-3891/a000005 
Collardeau, F., Bin Aftab, M. U., Jibeen, T., \& Woodin, E. (2021). Pakistani immigrants' nuanced beliefs about shame and its regulation. International Perspectives in Psychology: Research, Practice, Consultation, 10(1), 25-38. https://doi.org/10.1027/2157-3891/a000004

Espada-Brignoni, T., \& Alfaro, F. R. (2021). Culture, subjectivity, and music in Puerto Rico: Bomba, plena, and the ousting of a governor. International Perspectives in Psychology: Research, Practice, Consultation, 10(1), 3-12. https://doi.org/10.1027/2157-3891/a000001

Hogrefe. (2020). Hogrefe and SUB Göttingen pave the way to Open Access [Press release].

Hakim, M., \& Liu, J. H. (2021). Development, construct validity, and measurement invariance of the para-social relationship with political figures (PSR-P) scale. International Perspectives in Psychology: Research, Practice, Consultation, 10(1), 13-24. https://doi.org/10.1027/2157-3891/a000002

Rucklidge, J. J., Afzali, M. U., Kaplan, B. J., Bhattacharya, O., Blampied, F. M., Mulder, R. T., \& Blampied, N. M. (2021).
Massacre, earthquake, flood: Translational science evidence that the use of micro-nutrients post-disaster reduces the risk of post-traumatic stress in survivors of disasters. International Perspectives in Psychology: Research, Practice, Consultation, 10(1), 39-54. https://doi.org/10.1027/2157-3891/ a000003

Published online February 17, 2021

\section{Stuart Carr}

Industrial and Organisational Psychology Programme School of Psychology

Massey University

Auckland

New Zealand

s.c.carr@massey.ac.nz 